\title{
México en sus regiones socioculturales deportivas*
}

\author{
Enrique RIVERA GUERRER0
}

\section{PRESENTACIÓN, JUSTIFICACIÓN Y PREGUNTAS}

El deporte es cultura, véase como la manifestación simbólica de las prácticas sociales o desde el producto dirigido a las masas; es una actividad en la que hay practicantes, espectadores, público, difusores, empresarios, mensajes. Podremos analizar cada uno de los elementos que, interconectados en los campos de organización de la sociedad (económico, político, cultural, social), ha sido desdeñado por los científicos sociales. Tal vez esto se debe a que lo tenemos todos los días, presentado como forma de actividad alienante. Pero cada dos años (ya sean Juegos Olímpicos o mundiales de fútbol) nos acordamos de esta actividad lúdica, de gran valía para la humanidad.

“¿Cómo puede explicarse que un fenómeno social que arrastra o atrae a millones de aficionados en el mundo entero no sea desentrañado y analizado por la ciencia social?", se pregunta Julio Mafud, específicamente respecto del fútbol. Según Norbert Elias y Eric Dunning, hay tres aspectos que han llevado al deporte a tener cada vez mayor importancia social; éstos son: 1) el hecho de que ha cobrado fuerza como una de las principales fuentes de emoción agradable; 2) el hecho de que se ha convertido en uno de los principales medios de identificación colectiva, y 3) el hecho de que ha llegado a constituirse en una de las claves que dan sentido a las vidas de muchas personas (Elias y Dunning, 1992:266). Los dos últimos puntos son los que destacamos en el presente artículo, con el deporte como identificador de una colectivi-

\footnotetext{
* Una primera versión de este trabajo fue presentada como ponencia al IX Encuentro del Consejo Nacional para la Enseñanza y la Investigación de las Ciencias de la Comunicación (Coneicc) realizado en marzo de 1997 en Santiago de Querétaro, México.
} 
dad regional y su incorporación en el habitus y consumo cultural de un público competente en dicho campo.

Por otra parte, nos hemos percatado de que la línea de investigación en el campo cultural deportivo ha sido poco abordado en México. Como dice Rodríguez, 1995:

La visión del deporte, hace algún tiempo dejó de ser superficial, porque las ciencias se han aplicado sobre él, ya buscando el resultado, la educación o, simplemente un mejor conocimiento de esa realidad sociocultural.

El deporte ha sido relegado a elementos de poca importancia sociológica. Norbert Elias y Eric Dunning (1992:13-14) apuntan que esta actividad:

... no se ha considerado objeto de reflexión e investigación sociológica porque se le ha encasillado en el lado que todos juzgan negativo dentro del imbricado complejo de dicotomías convencionalmente admitidas, como las que existen entre "trabajo" y "ocio", "mente" y "cuerpo" (...) Es decir, en términos de la acentuada tendencia occidental hacia el pensamiento reduccionista y dualista, (...) es catalogado como una actividad trivial, recreativa, orientada hacia el placer, que emplea el cuerpo más que la mente y que carece de valor económico. En consecuencia, no se considera que plantee problemas sociológicos de importancia comparable a los relacionados con los "serios" temas de la vida económica y política. Y sin embargo, a pesar de su abandono comparativo, el deporte constituye razonablemente un campo de considerable importancia social -que al menos en la medida en que los sociólogos asuman con seriedad que la suya es una ciencia englobadora de la sociedad que se ocupa de las sociedades en todos sus aspectos- requiere teorización e investigación sociológicas.

En cuanto a las ciencias de la comunicación, Claudia Benassini encuentra que el binomio deporte-televisión

ha mostrado un interés creciente por parte de los investigadores, pero constituye una veta todavía poco explorada por los estudiantes de las carreras de comunicación quienes, dado su interés en el tema y sus derivaciones, pueden hacer múltiples aportaciones.

$\mathrm{Al}$ adentrarnos en el tema deportivo como objeto de estudio y la difusión periodística, un primer punto de partida bien puede ser la ciudad de Hermosillo, Sonora, situada al 
noroeste del país. Encontrar los elementos aquí presentados para la delimitación de las zonas sociorregionales en México fue -en muchas de sus partes- producto de la observación realizada en los viajes que hemos tenido la oportunidad de hacer.

\section{CRÓNICA PARA ILUSTRAR}

La música de la banda sinaloense se escucha a varias cuadras a la redonda del estadio de béisbol de Hermosillo. Es la pausa entre ining e ining, cuando uno de los equipos contendientes se dispone a tomar su turno al bat, y el otro se acomoda para soltar los brazos sobre el diamante.

Son los días fríos de otoño. Aquí la gente bebe otra marca de cerveza y, además de las palomitas, las frituras de harina de trigo, mejor conocidos como "duros", los refrescos, las papitas, los cacahuates y los cerillos, se venden tacos de carne asada, burritos de machaca y quesadillas, que, como su nombre lo sugiere, son de queso. Es una tarde-noche de béisbol de la Liga Mexicana del Pacífico en la capital del estado de Sonora.

El estadio Héctor Espino González luce una entrada regular; las causas pueden ser el clima frío de la estación o el hecho de que el equipo local tiene una temporada perdedora. Por el sonido local sigue la música con la melodía El sinaloense, que suena a todo volumen, destacando el sonido de la tuba y la tambora. En Hermosillo se aprecia un gusto musical compartido por toda la región del Pacífico norte, tan arraigado culturalmente en sus habitantes como el deporte que esa noche se juega, el béisbol.

¿Por qué se identifica a la región noroeste con el béisbol?, ¿por qué hay fútbol en Tijuana, Baja California?, ¿por qué el básquetbol es el deporte de arraigo en el estado de Chihuahua?, ¿cómo es que se forman más futbolistas profesionales en el Distrito Federal y los estados de Jalisco y Guanajuato?, ¿por qué en los estados de Sonora, Sinaloa y Veracruz nacen más beisbolistas?, ¿qué sucedió en la ciudad de Hermosillo, considerada como ciudad beisbolera, que hacia 1994 había más niños (7 de cada 10) jugando al fútbol?, ¿por qué en la ciudad de México el tipo de programación televisada favorita es el relacionado con el deporte (con un 18\% de preferencia)?, ¿qué características hay en el norte de Sonora para que sea basquetbolero y en el sur para que sea beisbolero, mientras que en la franja fronteriza norte del estado de Tamaulipas también se comparte el gusto por el rey de los 
deportes, y al sur del mismo estado se juega el fútbol?, ¿̇algo tiene que ver la historia, el clima, la corpulencia física, el desarrollo empresarial y la inmigración con el deporte que se practica en cada una de nuestras regiones?

"Por las funciones sociales que el deporte cumple en nuestros dias, podemos hablar de éste como un bien cultural" (Vásquez, 1991:26). Pensemos en un bien cultural arraigado, con raíces históricas y tan diferente como cada manifestación particular a cada paso que demos sobre el territorio nacional. "Así somos los mexicanos. Además de jarochos, poblanos, michoacanos o regiomontanos nuestro corazón es chiva, águila, cementero, rayo, puma, potro, etcétera" (Hernández, 1996:4).

\section{CULTURA Y COMUNICACIÓN}

El concepto de cultura es inseparable del hombre, sus acciones y su organización, sus objetos y sus manifestaciones simbólicas; ésta “... es dinámica y se haya envuelta de manera permanente en el acontecer histórico y en la actividad mental de los individuos" (Gil, 1993:126). Este carácter es el que nos podrá ayudar en esta investigación, donde la entenderemos como la manifestación simbólica de las prácticas sociales.

Cuando se habla de comunicación, apunta González (1994):

... suele hacerse dentro de dos sentidos: a) como práctica cultural, o sea como productos de comunicación que materializan y vehiculizan ciertos sentidos, y b) como proceso en el que complejamente se elabora la relación de comunicación y sus productos.

Parafraseando al autor citado, tendremos que volver visible cómo se ha forjado, desde cuándo y en qué diversos espacios nuestro objeto de estudio: la identificación regional

1. Eduardo Andión en clausura del VIII Encuentro del Consejo Nacional para la Enseñanza y la Investigación de las Ciencias de la Comunicación (Coneicc), San Luis Potosí, México, marzo de 1995. del deporte en México.

La cultura también es tradición, no solamente ancestral, hecha por otras comunidades en la historia. Existen tradiciones contemporáneas, esto vale igualmente en relación con el deporte; “¿Cómo es que se ha constituido la tradición del béisbol en la costa del Pacífico o en la costa del Golfo de México; por qué se constituye la tradición del fútbol en el altiplano?"1.

Según Antonio Alcoba, probablemente no exista en nuestra sociedad una actividad generadora de más símbolos 
y signos que el deporte. La propia actividad necesita de una serie de ademanes y gestos; la vestimenta de cada disciplina es diferente, así como los emblemas y logotipos de clubes, etc. Pensamos que esta proliferación de colores y logotipos, de símbolos, pasa de generación a generación al seguir éstas a los clubes. Nos indica también:

Pero una cosa es clara: el deporte ha generado un lenguaje propio con variantes lingüísticas que, a su vez, han enriquecido el lenguaje del hombre. Es decir, su práctica originó una serie de expresiones y esos vocablos, al multiplicarse y expandirse, formaron un idioma particular de la actividad deportiva.

\section{PÚBLICOS, HABITUS Y OFERTA CULTURAL}

Por público cultural entendemos a los agentes sociales no especializados que poseen las disposiciones (inculcadas o adquiridas) con las que son capaces de evaluar, apreciar y valorar los discursos y los objetos de una oferta cultural. Éstos están incorporados por el habitus, que configura esquemas de percepción, orientación y acción. Para González, (1994):

Es el origen y base de los estilos de vida, se incorpora durante la socialización en la vida familiar, y se va modulando y afinando en función de su contacto con nuevas situaciones y ofertas.

La oferta cultural es la presencia en el ambiente geográfico de posibilidades de acceso a los bienes culturales, posibilidades ofrecidas, entonces, por el campo cultural, entendido como el sistema de relaciones sociales especializadas en la generación, la presentación y la difusión de las representaciones sociales. El habitus "cambia y se transforma en [la] medida [en la] que, en una sociedad específica, operan condiciones que la distinguen [con] respecto a otras", (Manriquez, 1994).

\section{LA REGIÓN}

De acuerdo con Claudia Benassini, por televisión "en las transmisiones regionales y estatales el béisbol ocupa un lugar central, a diferencia de lo que ocurre en las transmisio- 
nes nacionales". Creemos que las llamadas transmisiones nacionales, al ser generadas desde la capital del país, difunden el deporte de arraigo de la región centro del territorio nacional. En cambio, la tradición del béisbol en otras zonas regionales "obliga" a las televisoras de la misma magnitud a transmitir este deporte en su lugar de influencia.

La región es otro de los conceptos centrales en esta investigación, según Ocampo (1996:44):

... tiene tal cantidad de aristas para su comprensión,
que seria dificil incorporarlos en toda su extensión.
Ellos van desde fenómenos geográficos, ecológicos,
lingüísticos, étnicos, políticos, hasta actividades
económicas y procesos culturales y sociales.

En estos procesos consideramos inserto al deporte que, pensamos, es particular de regiones específicas del país de acuerdo con lo que analizaremos más adelante.

Ocampo dice que una definición simple del concepto región es la de ser un espacio geográfico demarcado. Lo regional "da idea de geográfico, pero aquí no habrá de identificarlo como territorio físico, que aunque lo comprende, no se agota en él". Comprendemos que la región sociocultural va más allá de ciertos límites observables fisicamente (características naturales o las fronteras políticas). Ocampo, (1996:43) continúa:

podemos hablar mejor de un espacio definido por sus características similares que le confieren relativa autonomía. Mientras que lo geográfico nos proporciona el horizonte epistemológico territorial para los estudios regionales.

2. E. J. J.

Buytendijk. "El fútbol, estudio psicológico", citado por Mafud.

\section{REGIÓN SOCIOCULTURAL, TRADICIÓN Y DEPORTE}

Una de las manifestaciones de cultura se presenta en la memoria colectiva como tradición. En nuestro caso trataremos de descubrir el deporte como actividad arraigada en las distintas regiones de México, con énfasis en dos deportes, según el desarrollo histórico de las regiones donde se practica y goza el gusto por el fútbol y el béisbol. "Es preciso darse cuenta que el interés y el deseo de practicar un determinado deporte son expresión de una serie de inclinaciones que tienen profundas raíces" 2 . 
Es un hecho que la tradición, para ser tal, debe renovarse, si no desaparecerá; así, se preservará gracias a la memoria y los recursos de la población que la mantendrá viva. La región o procedencia geográfica es una de las variables en las mediaciones de referencia ${ }^{3}$ del sujeto receptor. El hecho de que Hermosillo sea considerada como ciudad beisbolera, y que ahí, al referirse a los "sureños" del país, se les identifique con el fútbol, nos hace reflexionar sobre las respectivas incorporaciones del deporte en la memoria colectiva y el sistema de las disposiciones que interiorizan los gustos, las prácticas y los estilos de vida. Según Gilberto Giménez:

la región sociocultural nace de la historia, de un pasado vivido en común por una colectividad, asentada en una porción de territorio. De este origen se deriva un estilo de vida en particular, que confiere identidad a la colectividad considerada ${ }^{4}$.

Además, se puede pensar que la región es originada por los significantes primarios de la simbología, ligados a la territorialidad (factores naturales y ecológicos), elevando a la dignidad de símbolos las condiciones territoriales de la región.

En nuestro estudio relacionaremos este concepto con las particularidades territoriales climáticas, que determinan cierta exigencia de desgaste físico para practicar determinado deporte. El esfuerzo corporal para la puesta en práctica del deporte es facilitado o no por las condiciones climatológicas de las respectivas regiones. Le sigue el modelo étnico familiar, "identificación que se remite a un pasado, a un patrimonio, y a una herencia cultural compartidos" ${ }^{5}$, tal como lo expondremos con el desarrollo histórico del deporte en las regiones de México, y con las influencias de personajes y grupos extranjeros que, ligados simbólicamente a sus comunidades, promovieron su deporte en nuestro país.

Le siguen la proliferación de los símbolos secundarios (la música, la alimentación, las fiestas, el tipo humano característico de la región, entre otros. De lo anterior surge la identificación sociorregional en la relación de los habitantes con ésta "en el proceso subjetivo que genera un sentido de pertenencia y cierto grado de lealtad con la región"6.

Con lo expuesto y considerando que "las prácticas culturales tienen expresiones únicas para el caso de un espacio social demarcado territorialmente" ${ }^{\text {, }}$, determinamos que existen regiones que se identifican con cierta disciplina deportiva, como lo hemos entendido: el deporte incorporado en el habitus, "primeramente encauzado en el núcleo familiar"8.
3. Véase la obra de Guillermo Orozco

Gómez sobre mediaciones en el proceso de recepción televisiva.

4. Giménez Montiel, Gilberto. "Apuntes para una teoría de la región y de la identidad regional". Estudios sobre las culturas contemporáneas. Vol. VI, No 18. México: Universidad de Colima, 1994, pp. 165-173

5. Ibídem, p. 165.

6. Ibídem, p. 169.

7. Manríquez, Miguel. "El consumo cultural". Revista del Colegio de Sonora. Año V, No 8. Hermosillo, Sonora, 1994, pp. 101-106,

8. González, Jorge

A. "La transformación de 
las ofertas culturales y sus públicos en México". Estudios sobre las culturas contemporáneas. Vol. VI, N ${ }^{\circ} 18$. México: Universidad de Colima, 1994.
9. Ibídem.

10. Conade/SEP: Ley de Estimulo y Fomento del Deporte. México DF: Unidad Editorial de la Conade, 1991, 37 pp.
Al hacer el cruce de variables con el dato de los primeros partidos de fútbol y béisbol en México, encontramos que la tradición y la identificación de ciertos deportes en las distintas regiones de nuestro país coincide con su particular desarrollo histórico. En esta investigación intentamos saber si esto se realiza en la práctica hereditaria y la apropiación de sentido en el encauce familiar de las comunidades y regiones en su desarrollo histórico. Como ya lo hemos señalado, la región sociocultural nace de la historia, de la herencia, de un pasado vivido en común. Sumergiéndonos en la historia buscaremos las razones que nos permitan explicarnos lo que ocurre hoy en dia, al estudiar el pasado en relación con un proyecto futuro.

Consideramos la historia de los agentes y los campos culturales como imprescindibles, dentro de la multidimensionalidad que existe para tratar de comprender la formación de los públicos y las ofertas culturales, ya que:

\begin{abstract}
Toda práctica de elección, valoración, lectura y "consumo" de bienes culturales se cruza por lo menos en dos trayectorias, a saber la historia de las estrategias, producciones y productos de los agentes y las instituciones especializadas en la cultura, entretejida con la historia de las disposiciones de los agentes que se han convertido en sus públicos en calidad de "consumidores", de miembros, de fieles, de fans, de seguidores, de votantes, de militantes ${ }^{9}$.
\end{abstract}

El pasado define conciencia histórica, hábitos y costumbres. Como lo hemos entendido, la primera forma de encauce del habitus es la familia, que nos dictará los caminos posibles de las formas y los modos de vida; por ello es importante referirnos a la historia en los orígenes del habitus, de las ofertas y de las instituciones del campo cultural referido, el deportivo.

\section{BREVE HISTORIA DEL DESARROLLO DEPORTIVO EN MÉXICO}

En la Ley de Estímulo y Fomento al Deporte ${ }^{10}$ de la Conade se apunta que en todo el siglo pasado cobra importancia la charrería. Ésta exige un amplio número de habilidades y conocimientos, y utiliza una terminología compleja para los individuos que la practican. En México, la presencia de grupos de marinos extranjeros, de trabajadores de empresas de origen inglés, alemán, holandés y norteamericano, determinó 
la introducción en nuestro medio de la práctica de deportes a los que no estábamos acostumbrados. Así, en 1877, en el puerto de Guaymas, Sonora, se jugó por primera vez el béisbol. En 1898, en la ciudad de Pachuca, Hidalgo, se jugó por primera vez el fútbol $\mathrm{y}$, a finales del porfiriato, los ingleses ya practicaban el criquet, el tenis, el polo y el golf.

Tomás Morales F. en la Enciclopedia del béisbol mexicano $^{11}$, realizó una cronología del béisbol en nuestro país, y se refiere al momento histórico que representa el primer juego de este deporte ocurrido en suelo mexicano. Son las regiones que se proclaman beisboleras las que pelean el honor de ser los primeros puntos donde se jugó el llamado rey de los deportes sobre tierras mexicanas.

El dato más exacto acerca de dónde se jugó por primera vez un partido de béisbol habla de que fue en Guaymas, Sonora, en 1877, y lo hicieron marineros norteamericanos que se encontraban de visita en el puerto. Se asegura que en el mismo año, pero en Nuevo Laredo, Tamaulipas, con la construcción del ferrocarril por parte de norteamericanos, comenzó el gran pasatiempo. Años más tarde, le tocó el turno al municipio de Cadereyta, Nuevo León, también por causa de la obra ferroviaria, al mando del coronel Tradwell Ayres Robertson, quien otorgó el día feriado por un aniversario más de la independencia estadounidense; los trabajadores comenzaron a jugar durante el día de asueto, justo el 4 de julio de 1889. Por otra parte, la península de Yucatán conoció pronto este deporte debido a su proximidad con Cuba-donde ya jugaban al béisbol-, allá por los días de 1890. Además, las giras que conjuntos profesionales cubanos realizaban por la región contribuyeron a que el béisbol fuera el deporte de arraigo en esta península.

En cuanto al fútbol, ocurrió lo siguiente.

\begin{abstract}
Nuestro país, a raíz de su movimiento libertario de 1810 , quedó en bancarrota. En 1823, el tercer Conde de Regla buscó en Inglaterra inversionistas para rehabilitar sus minas; para ello se constituyó en Londres, en 1824, la Compañía de Aventureros de las Minas de Real del Monte, cuyos socios ingleses trajeron consigo tecnologia, como el sistema de bombeo (...) también trajeron su deporte favorito, el soccer, reglamentado por ellos. El campo ubicado frente a la mina de Dolores es el primer lugar de nuestro país donde se jugó este deporte ${ }^{12}$.
\end{abstract}

El comentarista deportivo Ángel Fernández afirma que Soccer! en labios de los industriales ingleses, llevó al fútbol por todo el mundo, así como balones y reglas, y hasta unifor-
11. Treto Cisneros, Pedro. Enciclopedia del béisbol mexicano 1992. México DF: Revistas deportivas. S.A. de C.V., 1992.

12. "Los pastes de Real del Monte". México Desconocido 232. México DF, noviembre de 1996 , pp. 72-76. 
13. Giménez Montiel. Op. cit.

14. González. Op. cit. mes; tal fue el caso de México. En 1900 los muchachos del Real de Minas de Pachuca, se lanzaron animados por el viejo grito inglés del ¡hipp... hipp... hurra! Como contagio los otros ingleses se alinearon en el Orizaba y les siguieron los de Puebla... el fútbol empezó a rodar su balón en 1902, cuando aquellos ingleses que desembarcaron para trabajar en las minas de Pachuca y en los telares, vieron las viejas estampas con la acción, y sintieron la nostalgia y "se pusieron a dar voces".

Según otro dato, en 1900 los técnicos y mineros de la Compañía Real del Monte fundaron el Pachuca Athletic Club, primer equipo de fútbol en la República. Dos hombres notables por el impulso que dieron al fútbol en México fueron Percy C. Clifford y Robert J. Blackmore, pues trajeron las primeras normas del juego y los primeros balones reglamentarios. En la ciudad de México los primeros clubes en formarse fueron el Reforma Athletic Club, el British Club, en 1901, y el Mexico Cricket Club, todos integrados por ingleses. En Orizaba nació el Orizaba Athletic Club, integrado por escoceses. De 1902 a 1912 los ingleses practicaban en forma regular el fútbol en México. El Pachuca Football Club y el Reforma Football Club estaban integrados por británicos. ¿Se identificaban por su región de origen?

Como nos hemos podido percatar en los párrafos anteriores, "los inmigrantes todavía ligados simbólicamente a sus comunidades territoriales de proveniencia" 13 , con cierta disciplina deportiva incorporada en su habitus, llegan a México, y como grupo nacional, se identifican con su deporte. Esto, para los mexicanos de ese entonces, representó una nueva oferta, la que se constituyó en una segunda forma de moldeamiento del habitus "que se va modulando, afinando y refinando en función de su contacto con nuevas situaciones, estructuras y mercados"14.

La Ley de Estímulo y Fomento al Deporte señala que lo anterior, aunado al desarrollo empresarial del país, en particular de Sonora, Veracruz, Guanajuato, Hidalgo, Nuevo León y otros puntos de México, propició el apoyo para la formación de los equipos locales, que se dedicaron a la práctica de los novedosos deportes, entre ellos el boxeo, la lucha, las carreras de caballos y el frontón de mano. Las diferentes organizaciones que fundaron los extranjeros en México generaron el nacimiento de asociaciones, federaciones, empresas o asociaciones de empresas que con el tiempo y su desarrollo promovieron el crecimiento de diversos campos en la práctica del deporte. Asimismo, nace el deporte como espectáculo y, consecuentemente, el deporte profesional. 
Es decir, se crea el campo cultural deportivo, compuesto por instituciones y agentes especializados que ofertan el deporte a los diversos públicos. El acceso que tiene el público a la oferta varía de una región a otra, como lo hemos visto en el desarrollo histórico.

\section{EL FÚTBOL COMO FACTOR DE IDENTIFICACIÓN REGIONAL}

Acerca del sentido de identificación que motiva el fútbol en los habitantes de una región determinada, se han levantado argumentos que a la vez son justificantes de nuestro objeto de estudio, en la línea de investigación, comunicación y cultura.

El fútbol es un elemento de la cultura de los pueblos. El deporte como actividad humana de competencia, ocio activo y entretenimiento se puede analizar desde la óptica cultural. Así, Jorge González (1994:62) apunta que alrededor del concepto cultura

... se juegan cuestiones (...) de búsqueda y autorrepresentación de identidades (...) porque la cultura organiza y representa un nosotros muy plural que está ligado no sólo a la razón sino a las pasiones y a las mismas vísceras.

¡Qué deporte más universal, generador de pasiones y de identidad colectiva que el fútbol!

Este objeto de investigación parte de las primeras observaciones que hicimos acerca del deporte, sobre el orgullo que puede sentir una población por un equipo deportivo que los representa, la resignificación y afirmación de lo propio, del terruño, la región y, más allá, de la nación; sentimientos que están latentes en la cultura y que son despertados o, mejor dicho, exteriorizados durante el transcurso de un partido de fútbol, cuando nuestro equipo, que lleva los colores de nuestra bandera, de nuestra institución o de nuestra ciudad, se juega el honor de la colectividad representada en la lucha contra otros.

Pablo Alabarces (1996:19) señala:

... hablar y decir fútbol convoca a la tentación de decir nosotros cada vez que hablamos de clases populares. Uno habla de sí y de su grupo, de sus amigos y relaciones, de su historia y de sus afectos. 
El fútbol es un deporte colectivo que se juega sobre una cancha rectangular donde dos equipos se enfrentan y, lo que nos interesa, tienen que ser diferentes. Sus uniformes se deben diferenciar, caracterizando a un equipo respecto de otro, sin confusiones. Incluso cuando los equipos contendientes tienen colores similares, uno de ellos debe de cambiar su camiseta por otra que contraste con la camiseta del oponente; es decir, lo que se busca es que se identifique plenamente quién pertenece a un conjunto y quién a otro. Identificación y diferencia de los grupos que también se presenta entre localidades, regiones y naciones.

La observación anterior la ligamos con lo que nos dice Ignacio Ramonet:

15. Ramonet, Ignacio citado por Sonntag, en "Deporte e identidad nacional. Fútbol, simbolo de virtudes alemanas". Le Monde

Diplomatique. Año 1, $\mathrm{N}^{\circ} 6$, noviembrediciembre de 1997.

16. Roberto DaMatta citado por Medina Cano.

17. Ibídem.

18. Auge, Marc citado por Medina Cano.

\begin{abstract}
... más que cualquier otra disciplina deportiva, el fútbol tiene una fuerte resonancia identitaria y afectiva, a escala nacional; sigue siendo amplificador de pasiones nacionales que convierten al equipo nacional en el depositario de una enorme inversión simbólica ${ }^{15}$
\end{abstract}

Con respecto al sentido de identidad regional que genera un club de fútbol, Roberto DaMatta señala que la lógica simbólica permite descubrir cómo el deporte como medio permite la expresión de algunos valores de la sociedad ${ }^{16}$. El fútbol “... es generador de identidad colectiva. A través del fútbol se puede experimentar el país, la nación o la idea de una comunidad como algo visible, físico y distinto" ${ }^{17}$. Medina Cano indica lo siguiente:

El fútbol es un vehículo de socialización, un sistema que con sus símbolos permite la comunicación y la vivencia de valores colectivos. El deporte es una de las nuevas formas de sociabilidad en las ciudades actuales. Ante la crisis de las instituciones que figuraron la ligazón de la sociedad, el fútbol es una actividad que convoca y aglutina a los diferentes sectores que habitan una ciudad. En una ciudad descentrada y estallada habitada por diversidad de grupos y sectores sociales que sienten la ciudad desde referentes materiales y simbólicos diferentes, que suministra modos de arraigo y pertenencia precarios, es una identidad que suministra una forma colectiva de identidad. "Las adhesiones más vigorosas a la ciudad en el sentido más amplio de la expresión (pues los hinchas pertenecen a la región y no solamente a la ciudad stricto sensu) son de tipo deportivo y los simbolismos más elementales encuentran aquí (dos o tres letras, uno o dos colores) una vitalidad y una eficacia nuevas"18. El fútbol es un referente que aglutina, es un imaginario común que convoca a la gente a juntarse, a reu- 
nirse y reconocerse ${ }^{19}$. El fútbol forma parte de los procesos de identificación que los habitantes realizan con la ciudad o la región en la que viven. La relación con la ciudad o con la región se establece con referencia abstracta y arbitraria, los clubes deportivos son el mejor ejemplo de estos referentes abstractos ${ }^{20}$.

Aquí encontramos la aplicación de identificación local en un equipo de fútbol, más fino que lo regional; nuestro interés se centra en la identificación del Club de los Tiburones Rojos $^{21}$ en el puerto de Veracruz, pero a su vez la connotación es estatal, pues la representatividad del equipo se extiende a todo el Estado del mismo nombre.

Parafraseando a Medina Cano en la aplicación de nuestro marco de referencia, un triunfo de los Tiburones Rojos es una ocasión para afirmar públicamente los sentimientos de pertenencia al territorio y el orgullo de ser veracruzanos. Es una ocasión, asimismo, en la que se trata de afirmar la identidad referida a "la imagen estereotipada, enraizada en el tiempo, que una colectividad se da de sí misma y que desea transmitir a los otros"22.

Existe una imagen estereotipada que se tiene del jarocho en el resto del país y de la que nos percatamos al llegar a esta región, pues aunque se piensa que el jarocho pertenece a todo el Estado de Veracruz, ese nombramiento es sólo de los habitantes de la región denominada como "Las llanuras de Sotavento", cuyas localidades más importantes son el puerto de Veracruz, Boca del Río, Ciudad Cardel-La Antigua, Tlacotalpan y Alvarado.

Del marco de referencia geográfico con la identidad regional a través del fútbol, Medina Cano (1998) escribe que:

es un medio de expresión dramática de las tensiones entre grupos y regiones, de las divisiones sociales más significativas, de los diferentes tipos de antagonismos. Permite expresar lealtades particulares y las divisiones sociales y culturales. El campeonato nacional es un duelo entre regiones, entre ciudades, colores y estilos de juego que confirma la diversidad y la pluralidad cultural de un país.

Los duelos entre regiones vecinas son característica de lo anterior; ejemplificamos con el béisbol de la Liga Mexicana del Pacífico, en la que los encuentros llamados "clásicos" por la vecindad de las ciudades eran y son: Tijuana vs. Mexicali, Hermosillo vs. Guaymas, Ciudad Obregón vs. Navojoa, Guamuchil vs. Los Mochis y Culiacán vs. Mazatlán. Otro ejemplo
19. Barbero, Jesús Martín, citado por Medina Cano.

20. Ibídem.

21. En la costa del Golfo de México, actualmente nos abocamos a la tarea de investigar el sentido de identidad y pertenencia a una región, a través o a partir de un equipo de fútbol.

22. Bromberger, Christian, citado por Sonntag. Op. cit. 
23. "El clásico del norte" en Monterrey, Nueva León.

\section{4. "El clásico tapatío" en Guadalajara, Jalisco.}

25. "El clásico mexiquense" en el Estado de México.

26. "El clásico del bajio" en el Estado de Guanajuato. es la llamada "guerra civil" de la Liga Mexicana de Verano, con los Tigres capitalinos contra los Diablos Rojos de México, ambos del Distrito Federal.

En cuanto al fútbol de la Primera División en sus temporadas de 1998, los llamados clásicos son enfrentamientos entre equipos que pertenecen al mismo centro urbano y cuyos habitantes se dividen, atendiendo incluso a cierto estatus social si la preferencia se muestra hacia uno u otro equipo de la localidad. Por ejemplo: Monterrey vs. Universidad Autónoma de Nuevo León (UANL) ${ }^{23}$ y Atlas vs. Guadalajara ${ }^{24}$; de estos dos enfrentamientos se tiene testimonio que a Monterrey y Atlas los siguen la elite y UANL y Chivas de Guadalajara son los "equipos del pueblo" en sus respectivas metrópolis. Otros enfrentamientos son Toluca vs. Toros Neza ${ }^{25}$ y León vs. Atlético Celaya ${ }^{26}$, además del clásico del fútbol mexicano, América vs. Chivas de Guadalajara, que enfrenta a dos regiones productoras de futbolistas, según nuestras estadísticas, que son el Distrito Federal y el Estado de Jalisco.

Otros encuentros que causan especial atención son: América vs. Cruz Azul, Universidad Nacional Autónoma de México (UNAM) vs. Cruz Azul, y en algún tiempo, Veracruz vs. Puebla. Incluso con tintes políticos, el enfrentamiento entre Pumas de la UNAM vs. Tecos de la Universidad Autónoma de Guadalajara fue considerado como un choque entre la izquierda y la ultraderecha, respectivamente; más aún, en la misma capital jalisciense, cuando el juego era entre el desaparecido equipo de los Leones Negros de la Universidad de Guadalajara y los Tecos de la Autónoma, se presentaba una situación parecida.

Los equipos de fútbol están integrados por jugadores provenientes de distintas regiones geográficas y nacionales. En este punto Jorge Valdano (1997:145) indica que "es curioso que sigan funcionando los simbolismos y que los colores de una camiseta transmitan un sentido de pertenencia con independencia de quien se la ponga". Al referirse a la diversidad de orígenes nacionales de los jugadores pertenecientes a los clubes, Valdano señala igualmente que “... nadie parece indignarse lo suficiente por la escasa encarnación local”.

El caso alemán también nos puede hablar de lo anterior: Albert Sonntag apunta que el fútbol representa mucho más que un deporte colectivo. El fútbol tiene un impacto sobre la identidad colectiva de los ciudadanos. El fútbol se convirtió en uno de los escasos símbolos verdaderos generadores de identidad nacional.

La identidad se vive en el estadio y también sale a la calle. 
El estadio de fútbol es uno de los pocos espacios de desahogo de las emociones colectivas, en donde está tolerado expresar valores cuya expresión está proscrita socialmente en la vida cotidiana ${ }^{27}$.

Sonntag lo aplica al caso alemán al decir que

... entonces se comprende que este deporte haya ofrecido a los alemanes un terreno privilegiado en el cual tenían derecho a afirmar su identidad nacional, a vivir un sentimiento de orgullo y de pertenencia.

Con lo escrito hemos realizado los diversos argumentos que explican el sentido de identidad que puede conferir y reforzar el fútbol en sus dimensiones nacionales, regionales, locales o de grupos. Ahora ¿cómo refuerza el veracruzano esa identidad con el fútbol de los Tiburones Rojos?

Carlos Calderón (1998:35) indica de Luis de la Fuente que "como buen jarocho, su pasión fue el Veracruz, tanto que al desaparecer el equipo, "Pirata" Fuente decidió retirarse". ¿Qué es ser buen jarocho? Aquí, en estos renglones, Calderón hace referencia a un sentido que caracteriza al natural de esta región con énfasis en el todo o nada del ciudadano de Veracruz, o la llamada pasión jarocha, estereotipos colectivos que resignifican los habitantes de esta localidad.

\section{MAPA DE LOS EQUIPOS}

Al puntear sobre un mapa de la República notaremos cómo es que las regiones que nacen de la historia están presentes en clubes en la costa del Pacífico (Guaymas 1877), en Coahuila, Nuevo León y en el norte de Tamaulipas (Nuevo Laredo 1877 y Cadereyta 1889), y en el sur de Veracruz, Oaxaca y la península de Yucatán (1890). Al ver en el mapa del país las ciudades sede de los equipos que actualmente participan en las ligas de los deportes que hemos tomado como referencia, notamos la concentración de estos puntos que conforman las regiones socioculturales deportivas. Estos clubes representan la institución que oferta entretenimiento deportivo, a la vez que generan identificación con el público de la ciudad o la institución educativa a la que representan.

Los clubes de fútbol pertenecientes a la federación mexicana de este deporte, en campeonatos de Primera División y Primera División "A", están concentrados en su gran mayoría en el centro del país, al sur del Trópico de Cáncer y a la
27. Bromberger, Chistian, citado por Sonntag. Op. cit. 
28. Como lo hemos señalado, según Giménez, éstos representan a los inmigrantes ligados a sus comunidades de origen.

\section{Opinión} brindada por Sergio Zermeño al plantearle la hipótesis señalada en el VI Encuentro Binacional "Fronteras en Comunicación", efectuado el 21 y 22 de abril de 1995 en San Diego City College, San Diego, California, EE UU.

30. Los datos de los deportistas profesionales (quienes alguna vez fueron amateurs) son los que se pueden constatar, dado el seguimiento que se les brinda en el deporte de esta modalidad, por parte de enciclopedias especializadas, reportes de prensa y otras fuentes. latitud oeste del meridiano 98 $30^{\prime}$, que divide en dos partes (no iguales) el Estado de Veracruz y sitúa al Estado de Oaxaca fuera del cuadro que se aprecia en el mapa. El cuadro que marca el área futbolera de México en el centro del país, y las regiones noroeste, noreste y sureste que se representan como beisboleras, nos pone a reflexionar sobre los clubes situados en lugares que no pertenecen al área tradicional. Es así como planteamos el caso del actual equipo de Tijuana, Baja California, y el otrora Cobras de ciudad Juárez, Chihuahua de Fútbol; se tendrá que comprobar la hipótesis de que tanto Tijuana como ciudad Juárez captan el asentamiento de numerosos habitantes llegados de diferentes regiones del país hacia el norte, y que traen consigo el gusto por el fútbol, es decir, el habitus ${ }^{28}$. Esto se refleja en las entradas que hacen rentable al equipo local permitiendo la permanencia en una liga donde las grandes distancias para enfrentarse a los oponentes obligan a una fuerte inversión monetaria. Esta hipótesis la comentamos con el investigador Sergio Zermeño, de la Universidad Iberoamericana en Tijuana, Baja California, quien consideró que esta ciudad fronteriza es un mosaico de gente y la mayor parte de los habitantes no tiene raíces familiares ahí. A reserva de comprobación metodológica, el fenómeno migratorio es una de las causas por las que el fútbol obtiene la atención de la gente. Los empresarios locales ven en este entretenimiento deportivo un negocio rentable, con afición que lo sigue y lo apoya, lo que se ha manifestado en el hecho de sostener al equipo en esta ciudad bajacaliforniana, aun sin lograr su ascenso al máximo circuito del torneo de fútbol mexicano, la Primera División ${ }^{29}$.

\section{¿NACEN O SE HACEN?}

Encontramos un indicador más que nos puede ilustrar con números y por regiones el origen de los jugadores mexicanos profesionales ${ }^{30}$, comparativamente, en los deportes de fútbol y béisbol, uno del Campeonato Mexicano de Primera División y el otro de la Liga Mexicana de Béisbol. Los datos presentados son de los deportistas activos en ambas ligas durante las temporadas de 1990 y 1991.

El origen de los deportistas profesionales mexicanos nos indica que en su región se conjugan las características de gusto, apoyo, tradición e, implícitamente, el consumo cultural deportivo para el florecimiento de un deporte. Así, la región se muestra como una variable dentro de los procesos de apropiación y recepción de los mensajes. 
En este sentido se puede afirmar que "no es lo mismo nacer en una ciudad que tiene una oferta cultural muy alta"31, es decir, una oferta cultural alta en fútbol o en béisbol, que en una ciudad que no la tiene. En cuanto al origen de los jugadores de fútbol, destacan el Distrito Federal con 130 futbolistas nacidos ahí, le siguen las entidades de Jalisco con 88 y Guanajuato con 27. Mientras que en béisbol los estados de donde son originarios más deportistas de esta especialidad son: Sonora con 88, Sinaloa con 59 y Veracruz con 47.

Es bien sabido que para destacar en el básquetbol es de gran ayuda la estatura, lo que es distintivo de los norteños, sobre todo los chihuahuenses. No tenemos el dato del primer juego de básquetbol en México, pero al tomar como referencia la ubicación de los equipos que iniciaron la temporada 1994 de la Conferencia del Básquetbol Profesional (CBP), encontramos que la mayoría (11 de 16) estaban asentados en las entidades de la frontera norte, con especial énfasis en $\mathrm{Ba}-$ ja California (2), Chihuahua (3), Sonora (2) y Tamaulipas (2).

Observamos que los deportes señalados son producto de la influencia extranjera. ¿Qué se jugaba en México antes de estos nuevos deportes en aquellos años? El bien llamado deporte nacional: la charrería.

\section{EL CLIMA}

¿Existen otros factores para el arraigo de deportes específicos en una región determinada? Podemos añadir las condiciones climatológicas. Dentro de la comparación que hemos desarrollado con los deportes del fútbol y el béisbol, 1lama la atención que los estados que producen más beisbolistas (Sonora, Sinaloa y Veracruz) son de clima extremoso (cálido seco y cálido húmedo, respectivamente). Una explicación que tenemos que tomar en cuenta son las características del juego. En comparación con el fútbol, el béisbol es estático. Son justo los estados que producen más futbolistas (DF, Jalisco y Guanajuato) donde las condiciones climáticas son de temperatura media templada, lo que beneficia a un deporte que exige mantenerse en movimiento durante 90 minutos, con un descanso intermedio. ¡Cuántas veces hemos escuchado el pretexto de nuestra selección nacional de fútbol de que cuando pierden es porque hacía mucho calor!

Con planteamiento heurístico, al observar en el mapa la línea del Trópico de Cáncer, paralelo que especifica condiciones climatológicas sobre el planeta, comparemos en dónde se encuentran establecidos los clubes deportivos profesiona-
31. González, Jorge A. en curso-taller Focyp-Sonora. Hermosillo, Sonora, 15 de abril de 1996 . 
32. Carmona, Pedro, "Qué esto y qué lo otro". Periódico El Imparcial, sección Deportes, Hermosillo, Sonora, 10 de enero de 1996, p. 4,

33. Mejía Barquera, Fernando. “¡Piques! ¡Amagues!... ¡Frenos!... de la crónica deportiva en México". Revista

Mexicana de Comunicación 26. México DF:

Fundación Manuel

Buendia, noviembrediciembre 1992. les, así como las regiones en las que nacen más jugadores de estos deportes. Observar la característica de las condiciones climatológicas se originó cuando nos llamó la atención la similitud que existe entre las regiones beisboleras, tradicionalmente conocidas como consumidoras de cerveza. En cambio, en caso de las regiones futboleras se encuentra que coinciden con la región tradicionalmente consumidora de licores. O más claro aún: una cerveza fría para mitigar el calor, o un tequila para sentir la sensación de calor ante el frío.

\section{LA DIFUSIÓN DEPORTIVA}

¿Qué es primero : La TV que transmite el deporte y se gana el gusto de los públicos aficionados, o la preferencia de los públicos hacia un deporte que posteriormente se pasará en la TV? Se complica el separar los momentos y elementos que se complementan mutuamente. Actualmente, la televisión es un factor importante para la introducción del deporte en una región.

Por ejemplo, el mismo fútbol en Hermosillo ha venido tomando fuerza y ahora hay grandes cantidades de jugadores organizados en diferentes ligas y categorias en esta ciudad. Así se manifiesta en dos comentarios periodísticos que dicen:

... el fútbol soccer, es el deporte de mayor proyección en Sonora. Gran parte 'de la culpa' por así decirlo, son las transmisiones que a nivel nacional realizan las dos conocidas cadenas de televisión ${ }^{32}$.

El deporte como espectáculo masivo requiere de ciertas condiciones para desarrollarse: paz social, disposición del tiempo libre por una parte de la población, arraigo entre un sector importante de ella y la existencia de medios de difusión que se ocupen del espectáculo deportivo, lo critiquen, lo analicen, y contribuyan a crear ese peculiar star system que deviene la mitologia y hace a los deportistas brillantes trascender el momento que les toca vivir y formar parte de la historia ${ }^{33}$.

La disciplina deportiva no tradicional tendrá dificultades para florecer en el nuevo terreno regional. Pero al unirse las condiciones que permitan contar con la oferta cultural deportiva podrá hacer nacer la tradición. Así como lo dice la Enciclopedia del béisbol mexicano 1992: 
Siempre hemos expresado que el béisbol es un deporte agradecido. Está en deuda permanente con los que en el terreno de juego, la oficina, la crónica o las tribunas, han colaborado por hacerlo un deporte de arraigo popular ${ }^{34}$.

¿Fútbol en Hermosillo? ¿Cómo se ha venido popularizando el fútbol en esta ciudad? Consideramos dos factores: 1) la penetración de los medios de comunicación, particularmente la televisión y 2) el momento histórico: Miguel Mejía Barón.

En primer lugar tenemos la oferta a través de la televisión, presentando los contenidos a nivel nacional, y el aporte que generan los medios de comunicación para la popularización y masificación de los deportes, a decir de Joao Havelange: "Gracias a la TV, el fútbol se encuentra como el deporte número uno en el mundo"35. Además, un deporte no es masivo solamente por su difusión en los medios de comunicación de masas, sino también por la facilidad de su práctica. En seguida tomemos en cuenta que mientras haya resultados positivos en el terreno deportivo, y más aún en la representación simbólica del país: su selección nacional, como sucedió entre los años de 1993 y 1994, esto contribuye a poner la atención sobre este deporte. Tal parece que estos dos factores podrán suceder en cualquier parte del país. ¿’Por qué en Hermosillo se trae a jugar por primera ocasión al Tri ${ }^{36}$, y posteriormente se cuenta con un equipo ${ }^{37}$ de Primera División "A"? A estas preguntas se podrá contestar que tiene mucho que ver el desarrollo empresarial, y son los empresarios quienes traen esta oferta cultural y este espectáculo a la ciudad, que no contaba con la oferta futbolística de primer nivel. A decir de Pierre Bourdieu:

... las prácticas deportivas pueden ser descritas como la resultante de la relación entre una oferta y una demanda, con mayor precisión, entre el espacio de los productos ofrecidos en un momento dado y el espacio de las disposiciones sociales ${ }^{38}$

Lo que lleva a explicarnos por qué hoy en día hay más niños jugando al fútbol que al béisbol en Hermosillo, cuya población ha sido conocida tradicionalmente como beisbolera y basquetbolera. Lo accesible de la práctica y la proyección por televisión son dos de los principales factores para que ocurra esto. Un deporte popular no lo es necesariamente por su proyección a través de los medios de comunicación, sino
34. Treto Cisneros, Pedro. Op. cit.

35. Presidente de la FIFA. Declaración en el noticiario " 24 horas". México DF: Canal 2, Televisa, sección deportiva, 26 de marzo de 1996.

36. Efectuado el día 6 de diciembre de 1995 en el estadio Héroe de Nacozari. Juego en calidad de amistoso ante la selección Sub23 de Eslovenia

37. El 4 de enero de 1996 se anunció oficialmente que la franquicia se mudaria a Hermosillo, Sonora, desde Querétaro.

Uno de los argumentos para hacer el cambio de sede fue que en la ciudad queretana la afición no apoyaba al equipo aun cuando éste lograba obtener resultados positivos para su causa. Más tarde, las deudas no permitieron la estabilidad de la franquicia y no se inició el Torneo de Invierno de 1996 de la Primera División "A".

38. Bourdieu, Pierre. "Programa para una sociología del deporte". Cosas Dichas. Buenos Aires: Gedisa, 1988. 
por lo sencillo que representa su puesta en juego. Martín Estrella, primer sonorense en militar en la Primera División al final de la década de los setenta, nos dijo que

... lo más fácil es agarrar una pelota, poner dos porterías con piedras, y tenemos a cuarenta niños jugando y divirtiéndose. Otro atractivo del fútbol para los infantes es que para su ejecución se invierte mucha energía. Ellos quieren estar jugando, barriéndose, brincando. El fútbol es acción constante, y el niño quiere derrochar toda esa energía que trae acumulada. En cambio, el béisbol es un deporte más estático, ahí pueden llegar tres pelotas o no llegar ninguna. Además, la televisión ha sido un medio que ha influido para la proyección del fútbol en esta ciudad y Estado.

Con lo anterior lanzamos la hipótesis: dentro de unos 20 años más, al observar la gráfica de los orígenes de los deportistas profesionales mexicanos, ¿habrá un incremento dramático en el número de futbolistas nacidos en el Estado de Sonora? Lo que consideramos será producto del afinamiento del habitus y sus prácticas ante las nuevas ofertas culturales, en este caso, como lo hemos visto, las ofertadas por el campo cultural deportivo.

\section{INVESTIGACIÓN ACTUAL}

Creemos conveniente hacer una breve descripción de la investigación que actualmente nos ocupa, con el antecedente inmediato del artículo ya expuesto.

"El club de fútbol Tiburones Rojos de Veracruz como identificación sociocultural en los aficionados del puerto de Veracruz" es el título de la investigación que realizamos para obtener el grado de maestría en Comunicación.

La pregunta central que nos guiará en este trabajo es: ¿Cómo se construye el sentido de identidad y pertenencia a través de un club deportivo, en este caso los Tiburones Rojos, desde la perspectiva sociocultural en una región como la ciudad y puerto de Veracruz? A partir de ésta surgen las siguientes subpreguntas de investigación:

- ¿Cuáles son las condiciones socioculturales que influyen para que el fútbol sea popular en una región del puerto de Veracruz?

- ¿En qué elementos se materializa el sentido de identidad de la población veracruzana con respecto al fútbol? 
- ¿Qué papel juegan algunas instituciones (como el Estado y la iniciativa privada), así como la sociedad civil, en la oferta deportiva del fútbol profesional en el puerto de Veracruz?

- ¿De qué manera influyen los factores sociales (historia, desarrollo empresarial, inmigración) y naturales (condiciones climatológicas y orografia) en el campo cultural del fútbol profesional?

La presente investigación tiene por objeto de estudio el deporte del fútbol como identificación cultural en regiones específicas del país. El deporte es una práctica inserta en las demás actividades del ser humano, apunta Antonio Alcoba; nos abocaremos a analizar cómo es que se presenta la identificación en los habitantes pertenecientes a una región de México, el puerto de Veracruz, que entenderemos como el área conurbada de las ciudades y municipios de Veracruz y Boca del Río. Así, nuestro objetivo es conocer, a través de la oferta del fútbol jugado por el club Tiburones Rojos, cómo se configura la identidad regional en el puerto de Veracruz.

Para lograr lo anterior partimos de la siguiente hipótesis: La ubicación de los clubes deportivos profesionales y el desarrollo histórico de la oferta del campo cultural deportivo del fútbol en Veracruz propicia la formación del público (deportistas y espectadores) en el encauce y moldeamiento de los habitus en esta región sociocultural.

La propuesta metodológica será cualitativa y la técnica de investigación a utilizar será la etnografia. Con la etnografía observaremos y escucharemos información en una exhaustiva descripción del lugar y la gente para entender lo que sucede socialmente en esta región.

Somos nuevos habitantes de este lugar; se observó, escuchó y hemos detectado elementos sociales, materiales y naturales que identifican esta región del país. Con esta técnica nos daremos cuenta de lo que sucede a nuestro alrededor y lo apuntaremos en el diario de campo para trabajar a partir de nuestras descripciones.

La etnografía nos será útil con la observación detallada y analítica que se realizará de los públicos, sean espectadores o practicantes, así como en la experiencia y vivencias dentro de espectáculos deportivos en Veracruz. Con esta técnica describiremos etnográficamente el terreno en el que estaremos trabajando.

El presente es el segundo acercamiento a este objeto de estudio, en busca de alcanzar objetivos que no fueron desarrollados, y que consideramos podremos alcanzarlos con técnicas de investigación que arrojarán otra naturaleza de datos. 
Bibliografía

\author{
Alabarces, Pablo y María Graciela Rodríguez \\ 1996 \\ Cuestión de pelotas. Fútbol, depor- \\ te, sociedad, cultura. Buenos Aires: \\ Editorial Atuel.
}

Alcoba López, Antonio 1993

Cómo hacer periodismo deportivo. Madrid: Editorial Paraninfo.

Alponte, José María 1993

"Las cámaras de TV y el deporte". México DF: Diario El Nacional, sección $1 \mathrm{~A}$, pp. 1 y 10, 13 de marzo.

Bauer, G. y H. Ueberle 1994

Fútbol. Factores de rendimiento, dirección de jugadores y del equipo. México DF: Editorial Roca S.A.

Benassini Félix, Claudia

"Deporte y televisión: necesidad de acercarse a un binomio poco explorado". Manuscrito.

Bourdieu, Pierre 1988

"Programa para una sociología del deporte". Cosas Dichas. Buenos Aires: Gedisa.

1990

Sociología y cultura: los noventa. México DF: Conaculta-Grijalbo.

Dunning, Eric y Norbert Elias 1992

Deporte y ocio en el proceso de civilización. Madrid: Fondo de Cultura Económica.

Fernández, Ángel 1994

La historia fascinante. Esto es fútbol, el juego del hombre. México DF: Editorial Aguilar. 
"Es parte de una crisis. Del amor a la camiseta, a la guerra insólita". Magazine Deportivo. Año 7, N ${ }^{\circ} 86$ México DF, enero, pp. 20-24.

Galeano, Eduardo

1995

El fútbol a sol y sombra. México DF: Siglo Veintiuno editores.

Galindo Cáceres, Jesús 1994

Cultura mexicana en los ochenta. Apuntes de metodología y análisis. Colima: Universidad de Colima.

Galindo Cáceres, Jesús y Jorge González 1994

Metodología y cultura. México DF: Conaculta. Colección Pensar la Cultura.

García Canclini, Néstor (coordinador) 1991

El consumo cultural en México. México DF: Conaculta. Colección Pensar la Cultura.

Gil Olivo, Ramón

1992

Televisión y cultura. Hacia el caos sensorial. Vol. 1. Guadalajara, Jalisco: Universidad de Guadalajara.

Giménez Montiel, Gilberto 1994

"Apuntes para una teoría de la región y de la identidad región". Estudios sobre las culturas contemporáneas. Vol. VI, $\mathrm{N}^{\circ}$ 18. Colima: Universidad de Colima.

González, Francisco Javier 1991

Quién es quién en el fútbol mexicano. México DF: Editorial Planeta.

González, Jorge

Más (+) cultura(s). Ensayos sobre realidades plurales. México, DF: Conaculta. Colección Pensar la Cultura.

1994

"La transformación de las ofertas culturales y sus públicos en México". Estudios sobre las culturas contemporáneas. Vol. VI, No 18 , Colima: Universidad de Colima. 
Hernández Luna, Juan 1996

Koch, Karl

1981

Mafud, Julio

1967

Manríquez, Miguel

1994

Marco, Vicente

1981

Medina Cano, Federico

1998

Ocampo, Luis Fernando

1996

Olvera, Ramón

1973

Rivera Guerrero, Enrique 1996

"Entre la expectación y la práctica

Rodríguez López, Juan 1995

Sonntag, Albrecht 1997 deportiva (oferta, consumo cultural y mediaciones televisivas en Hermosillo, Sonora)". Tesis de licenciatura en Ciencias de la Comunicación. Hermosillo, Sonora: Universidad de Sonora.

Deporte y ciencia. Teoría de la actividad fisica. Barcelona: Editorial Inde Publicaciones.

El fútbol. El deporte espectacular, el espectáculo deportivo. México DF: Corporativo Mina S.A. de C.V.

Hacia una ciencia del deporte. Buenos Aires: Editorial Kapeluz S.A.

Sociología del fútbol. Buenos Aires: Editorial Americalee S.R.L.

"El consumo cultural". Revista del Colegio de Sonora. Año V, $\mathrm{N}^{\circ} 8$. Hermosillo, Sonora, pp. 101-106.

Historias del deporte. Madrid: Editorial Pentatlón, S.A.

“¿Panem et circensis?”. Manuscrito.

"Lo regional: punto de encuentro". Ciudades 29. México DF: RNIU, enero-marzo.

Remembranzas beisboleras. México DF: Litografia Universal.

"Deporte e identidad nacional. Fútbol, simbolo de las virtudes alema- 
nas". Le Monde Diplomatique. Año

$1, \mathrm{~N}^{\circ} 6$, noviembre-diciembre.

Treto Cisneros, Pedro 1992

Enciclopedia del béisbol mexicano 1992. México DF: Revistas deportivas S.A. de C.V.

Valdano, Jorge 1997

Los cuadernos de Valdano. Barcelona: Edit. El País-Aguilar.

Vásquez Henriquez, Alexis

1991

Deporte, politica y comunicación. México DF: Editorial Trillas. 


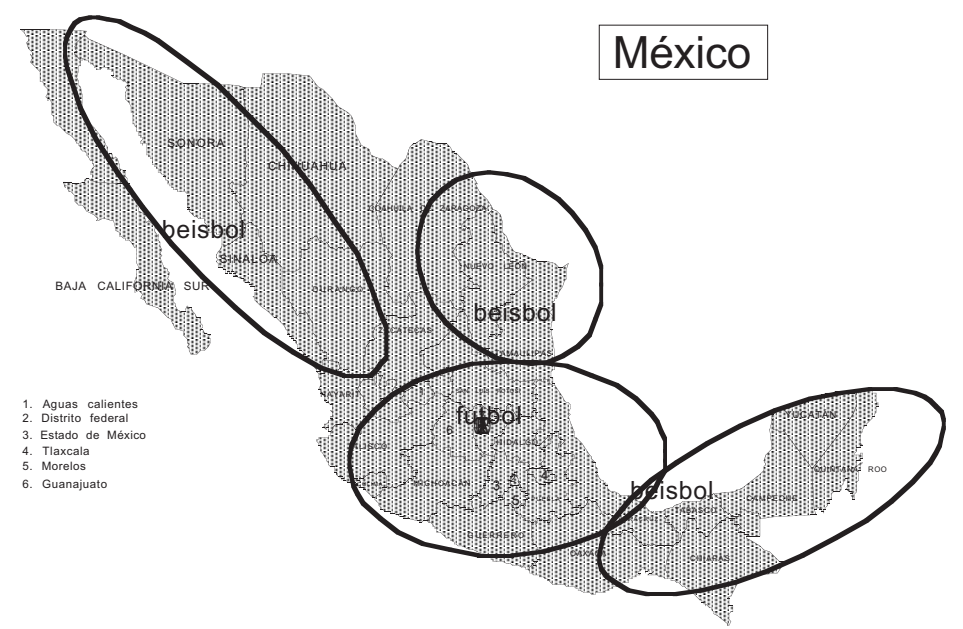

Estados de la república mexicana que conforman las regiones: Norte: Nuevo León y San Luis Potosí.

Norte-central: Aguascalientes, Chihuahua, Coahuila, Durango, Zacatecas.

Noroeste: Baja California, Baja California Sur, Sonora y Sinaloa.

Centro: Estado de México, Distrito Federal, Guanajuato, Hidalgo, Morelos, Puebla, Querétaro y Tlaxcala.

Occidente: Colima, Jalisco, Michoacán y Nayarit.

Golfo: Tabasco, Tamaulipas y Veracruz.

Península: Campeche, Quintana Roo y Yucatán.

Sur: Chiapas, Guerrero y Oaxaca.

Origen de deportistas mexicanos

(activos en 1990-1991)

\begin{tabular}{|l|c|c|}
\hline Región & Beisbolistas & Futbolistas \\
\hline Norte & 19 & 27 \\
Norte-central & 44 & 29 \\
Noroeste & 160 & 8 \\
Centro & 22 & 187 \\
Occidente & 33 & 115 \\
Golfo & 72 & 33 \\
Peninsula & 7 & 0 \\
Sur & 10 & 5 \\
\hline
\end{tabular}

Cantidad

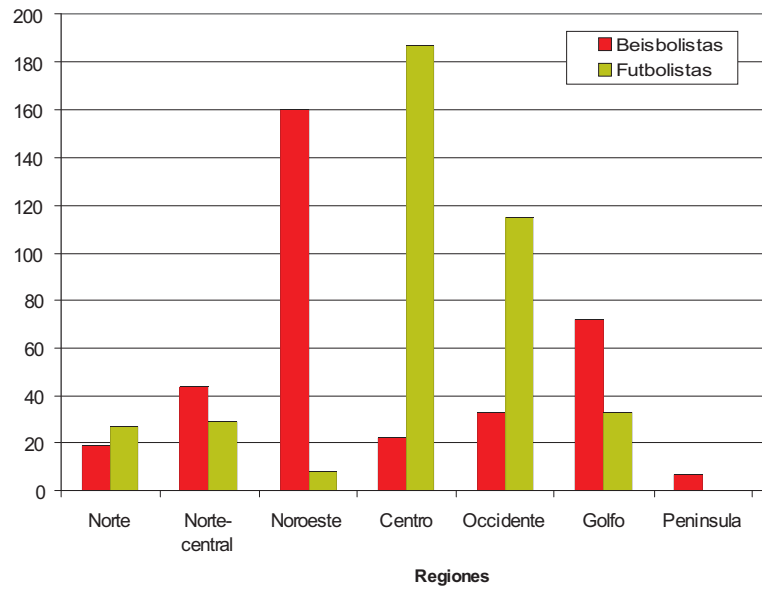

